\title{
Early Intervention in Breech Presentation to Reduce of Cesarean Section and Breech Deliveries
}

\author{
Tsuneaki Tsuzaki ${ }^{1 *}$, Kazuhiko Ozaki ${ }^{1}$, Kazuya Arata² and Kazuo Maeda ${ }^{2}$ \\ ${ }^{1}$ Yoka Municipal Hospital, Yabu, Japan \\ ${ }^{2}$ Tottori University School of Medicine, Yonago, Japan
}

\begin{abstract}
The effect of early intervention in breech presentation is investigated by outcomes of two indices: the breech delivery rate and the breech cesarean rate. Historically-controlled retrospective study was performed from 1985 to 2012 . We intervene the breech presentation with tocolysis and external cephalic version (ECV) after 32 weeks' of pregnancy and compared two indices before introduction of ECV (1985-87) and after (1986-2012). Statistical study was carried by kaisu are test and $P$ value less than 0.05 is significant. Utilized tocolytic agents were ritdor in hydrochloride and magnesium sulfate. ECV was performed after $24 \mathrm{hrs}$ in admission. Within enrolled case of 478 , one hundred and sixty two cases were office ECV was excluded due to no controls (unsuccessful cases). Adopted 316 cases of admission-controlled ECV was divided into two groups of ECV (245 cases) and no ECV (71 cases). Spontaneous version had occurred in 20 cases of ECV and in 58 cases of no ECV, so overall spontaneous version rate was $25 \%(78 / 316)$ and overall successful ECV rate was $66 \%$ (161/245) under low reversion rate of $2.8 \%(9 / 323)$. In this way, two indices of the breech delivery rate and breech cesarean section rate had reduced from 3.3 to $2.1 \%$ and from 21.3 to $12.7 \%$ respectively $(p<0.01)$. Furthermore we have not experienced serious complications. So we considered early intervention in breech presentation with tocolysis and ECV is useful for reduction of breech delivery and breech cesarean section.
\end{abstract}

Keywords: Breech presentation; Tocolysis; External cephalic version (ECV); Reversion; Breech delivery rate; Breech cesarean rat

\section{Introduction}

As breech presentation is one of high-risk factors due to relative high perinatal morbidity, elective cesarean section is applied to breech cases especially to primiparity, and first cesarean section destined second and/or third cesarean section. As our hospital has introduced intra-hospital midwifery from 1999 , reduction of cesarean section due to non-cephalic position is need. So we investigated retrospectively the rate of breech delivery and cesarean section rate before and after the introduction of early beginning external cephalic version (ECV) after 32 weeks' of pregnancy.

\section{Materials and Methods}

We have registered clinical data and outcomes of all obstetrical cases on database soft "Kiri ver8" from 1993 to now. This file contains 118 items in each delivery case. We conducted historically controlled retrospective study from 1985 to 2012 in Yoka municipal hospital which is one of the teaching hospitals in Hyogo prefecture in Japan (Figure 1). In this study, we had intervened in 478 breech presentations which contains 162 office-controlled ECV cases and 316 admission-controlled cases to compare the obstetric outcomes of pregnant women after successful external cephalic version (ECV period) with no ECV period (controls). First outcome is cesarean delivery rate and the second one is breech delivery rate. As unsuccessful ECV was not recorded at office, office-controlled ECV was excluded in the statistical study.

As almost spontaneous cephalic version occurred around 30 weeks of pregnancy, intervention in breech presentation after 32 weeks of pregnancy is indicated. We administered ritodrine hydrochloride per os to breech presentation at the office around 30 weeks of pregnancy and we applied office ECV to persistent breech presentation. Retained breech presentation after unsuccessful ECV at office had admitted and put in tocolysis after the informed consent (Figure 2).

The method of tocolysis is not only continuous drip infusion of ritodrine hydrochloride (16.7 66.8 $\mu \mathrm{g} / \mathrm{min})$ but also continuous infusion of magnesium sulfate $(1 \mathrm{~g} / \mathrm{hr})$.

During tocolysis, maternal heart rate maintained under $120 \mathrm{bpm}$ and biceps reflex was monitored and tachycardia more than 120 $\mathrm{bpm}$ and/or loss of biceps reflex is requirement of interruption or adjustment of tocolysis. After about 24 hrs later, non-stress test (NST) was performed for one hour and fetal wellbeing was confirmed prior to ECV. Chi-square test was used for categorical variables and $\mathrm{P}$ values under 0.05 were considered statistically.

\section{Results}

Between 1985 and 2012, 478 breech cases were enrolled in this study. One hundred and sixty-two breech cases attained cephalic version at the office (Figure 3) and 316 were attempted on admission (Table 1 and Figure 4). In the admitted cases, the overall success rate of ECV under tocolysis was 66\% (161/245) (61\% for null parity, $73 \%$ for multiparty: $\mathrm{P}<0.05)$ (Table 2$)$. Cephalic version rate only with tocolysis was $82 \%$ (58/71) (Figure 3). So overall spontaneous success rate with spontaneous cephalic version after unsuccessful ECV was $25 \%(78 / 316)$ (Figure 4).

On the other hand, reversion rate of the office controlled cases and the admission controlled cases were $4.3(7 / 162)$ and $1.2 \%(2 / 161)$ respectively (NS) (Figures 3 and 4). The breech delivery rate and

*Corresponding author: Tsuneaki Tsuzaki, Department of Obstetrics and Gynecology, Yoka Municipal Hospital, Yabu, Japan, Tel: 81-79-662-5555; Fax: 81859-22-6856; E-mail: t-tuzaki@hosp.yoka.hyogo.jp

Received January 22, 2014; Accepted February 04, 2014; Published February 12, 2014

Citation: Tsuzaki T, Ozaki K, Arata K, Maeda K (2014) Early Intervention in Breech Presentation to Reduce of Cesarean Section and Breech Deliveries. J Health Med Informat 5: 151. doi:10.4172/2157-7420.1000151

Copyright: ( 2014 Tsuzaki T, et al. This is an open-access article distributed under the terms of the Creative Commons Attribution License, which permits unrestricted use, distribution, and reproduction in any medium, provided the original author and source are credited. 


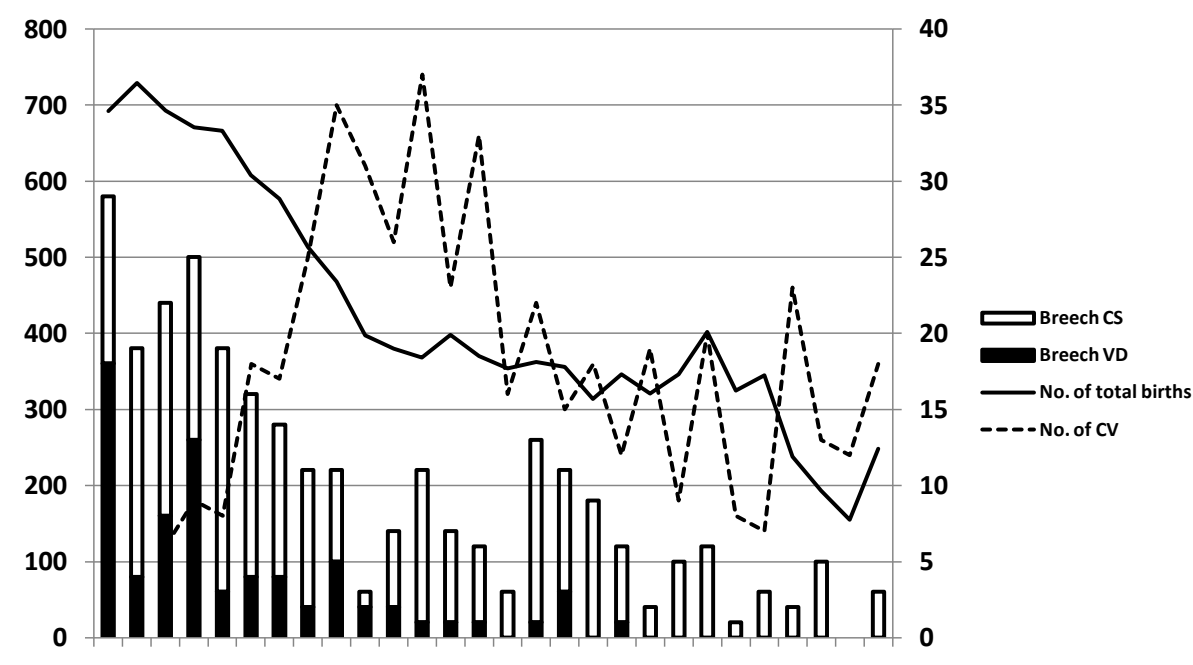

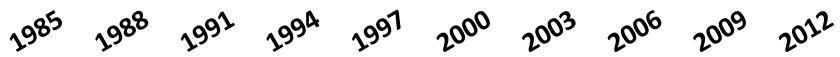

Figure 1: Trendgram of total births, breech births and No. of CV. CV: cephalic version, CS: cesarean section, VD: vaginal delivery.

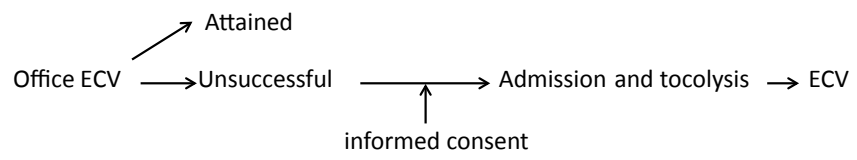

Figure 2: Flow of management for breech presentation.

\section{Attained ECV at office:162}

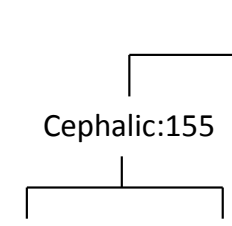

VD:151

$\mathrm{CS}: 4$

Revert to breech presentation:7

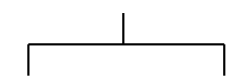

Breech VD:5

$\mathrm{CS}: 2$
Figure 3: Tree diagram demonstrating obstetrical outcomes of the office ECV. CS: cesarean section, ECV: external cephalic version VD: vaginal delivery.

\section{- Singleton breech presentation.}

- No previous cesarean section.

- More than 32 weeks of pregnancy.

- Less than 30 of BMI.

- No other risk factors such as oligohydramnios.

- No uterine fibroid.

- No uterine anomaly.

- No fetal dysfunction

Table 1: Clinical conditions for ECV.

breech cesarean section rate was reduced from 21.3 to $12.7 \%$ and from 3.3 to $2.1 \%$ respectively $(\mathrm{P}<0.01)$ (Table 3 and Figure 5$)$. We have not experienced serious feto-maternal complications such as placental abruption.

\section{Discussion}

External cephalic version (ECV) is a safe and effective intervention

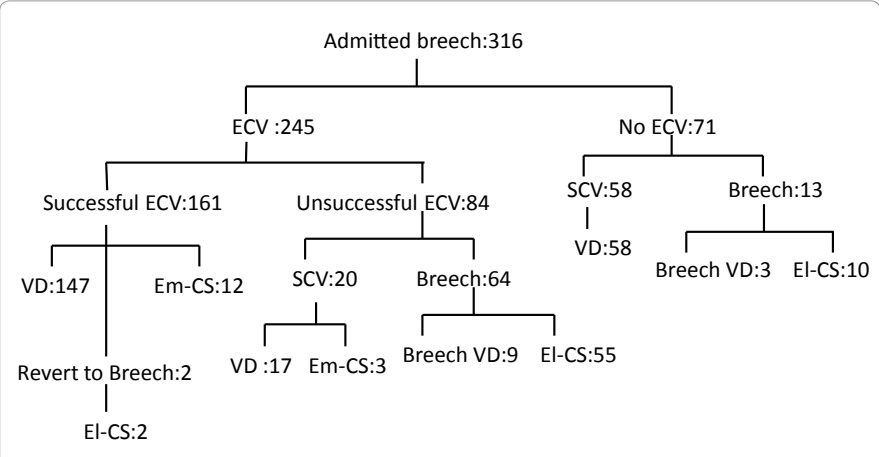

Figure 4: Tree diagram demonstrating obstetrical outcomes of breech presentation. ECV: external cephalic version, VD: vaginal delivery, SCV: spontaneous cephalic version. El-CS: elective cesarean section, EM-CS: emergency cesarean section.

that can prevent breech delivery, thus reducing the need for cesarean delivery [1]. Although almost previous reports have intervened in breech presentation at near term [2-4], we have intervened after 32 weeks of pregnancy because we thought that so later so more intrauterine volume, so lesser amniotic fluid and so more uterine rigidity which interfering factors on ECV. In fact, overall successful rate of near-term ECV is relatively low (41-51\%) to our success rate of $66 \%$ [2]. The significance of tocolysis in ECV is reported not only positively [5-7], but negatively [8,9]. According to high spontaneous cephalic version rate of $82 \%$ in no ECV cases and no serious complication with this technique, we confirmed that tocolysis is crucial before ECV.

Early beginning ECV(at between 34 and 36 weeks' gestation) showed reduce the risk of non-cephalic presentation at delivery and the rate of cesarean section compared with 37 to 38 weeks [10] which is consistent with our results. Even if delayed beginning ECV, reversion rate was reported as 6 [2] (6/98) 7\% [3], which is almost the same as our overall reversion rate of $2.8 \%(9 / 323)$. As the appropriate moment for ECV is not established in this way, we may select the moment near term every case condition.

From meta-analysis, ECV-related complication rate was $6.4 \%$ with 
Citation: Tsuzaki T, Ozaki K, Arata K, Maeda K (2014) Early Intervention in Breech Presentation to Reduce of Cesarean Section and Breech Deliveries. J Health Med Informat 5: 151. doi:10.4172/2157-7420.1000151

Page 3 of 3

\begin{tabular}{|c|c|c|c|c|c|c|c|c|}
\hline & \multicolumn{4}{|c|}{ ECV } & \multicolumn{4}{|c|}{ No ECV } \\
\hline & \multicolumn{2}{|c|}{ Successful ECV } & \multicolumn{2}{|c|}{ Unsuccessful ECV } & \multicolumn{2}{|c|}{ Spontaneous version } & \multicolumn{2}{|c|}{ Persistent breech } \\
\hline \multirow[t]{3}{*}{ Nulliparity } & \multicolumn{2}{|c|}{86} & \multicolumn{2}{|c|}{56} & \multicolumn{2}{|c|}{30} & \multicolumn{2}{|c|}{11} \\
\hline & VD & CS & VD & CS & VD & CS & VD & CS \\
\hline & 74 & 12 & $11(3)$ & 45 & 30 & 0 & 2 & 9 \\
\hline \multirow[t]{3}{*}{ Multiparity } & \multicolumn{2}{|c|}{75} & \multicolumn{2}{|c|}{28} & \multicolumn{2}{|c|}{28} & \multicolumn{2}{|c|}{2} \\
\hline & VD & CS & VD & CS & VD & CS & VD & CS \\
\hline & 73 & 2 & $15(6)$ & 13 & 28 & 0 & 1(1) & 1 \\
\hline Total & \multicolumn{2}{|c|}{161} & \multicolumn{2}{|c|}{84} & \multicolumn{2}{|c|}{58} & \multicolumn{2}{|c|}{13} \\
\hline
\end{tabular}

( ): No. of breech vaginal delivery

Table 2: Outcome of the admitted breech presentation.

\begin{tabular}{|l|c|c|}
\hline & No ECV period & ECV period \\
\hline No. of deliveries & 2114 & 9388 \\
\hline Breech VD & 30 & 43 \\
\hline Breech CS & 40 & 156 \\
\hline No. of CS & 188 & 1233 \\
\hline
\end{tabular}

VD: vaginal delivery, CS: cesarean section

No ECV period: 1985-87, ECV period: 1988-2012

Table 3: No. of deliveries and mode of delivery.

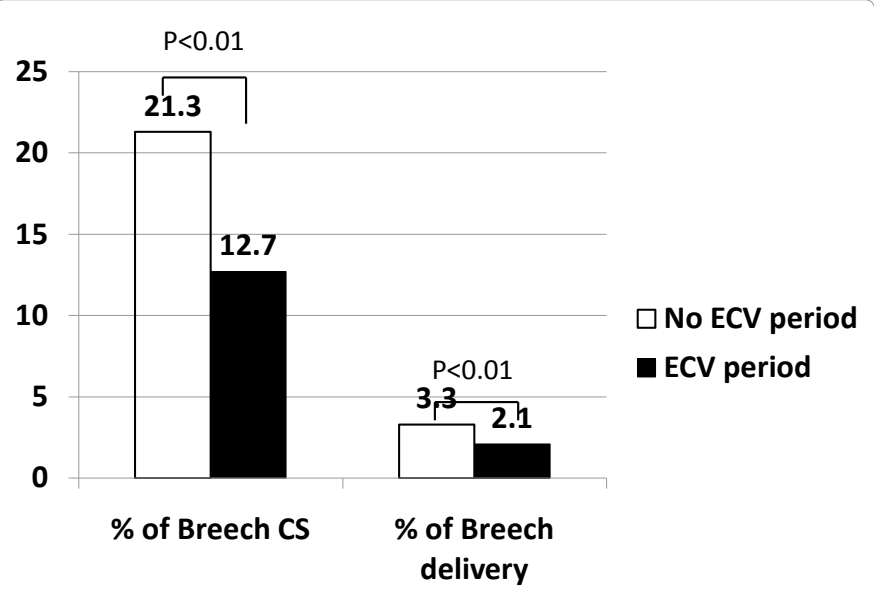

Figure 5: Rate of breech delivery and breech CS in the period of no ECV and ECV.

serious complication of $0.24 \%$ [11]. As unsuitable placental site namely anterior attachment, oligohydramnios and nuchal umbilical cord might interfere safety maneuver, ultrasound assessment of these conditions and FHR monitoring is crucial prior to and during ECV to prevent complications. We interrupt the maneuver when fetal bradycardia and/or maternal pain with maneuver occur. This decision will prevent serious complications due to ECV.

\section{References}

1. Rosman AN, Guijt A, Viemmix F, Rijnders M, Mol BW, et al. (2013) Acta Obstet Gynecol Scand. Contraindications for external cephalic version in breech position at term: a systemic review. Acta Obstet Gynecol Scand 2: 137-142.

2. Skupski DW, Harrison-Restelli,Dupont RB (2003) External cephalic version:an approach with few complications. Gynecol Obstet Invest 56: 83-88.

3. Impey L, Lissoni D (1999) Outcome of external cephalic version after 36 weeks gestation without tocolysis. J Matern Fetal Med 8: 203-207.

4. Rjinders $M$, Herschderfar K, Prins $M$, Van Veelen AJ, Schoenbeck $Y$, et al (2008) A retrospective study of the success, safety and effectiveness of external cephalic version without tocolysis in a specialized midwifery centre in the Netherlands. Midwifery 24: 38-45

5. Mohamed Ismail NA, Ibrahim M, MohdNaim N, Mahdy ZA, Jamil MA, et al (2008) Nifedipine versus terbutaline for tocolysis $n$ external cephalic version. Int J Gynaecol Obstet 102: 263-266.

6. Carlos OF, Steven LB, John CM, Cande VA, George DW (1997) A randomized placebo-controlled evaluation of terbutaline for external cephalic version ObstetGynaecol 90: 775-779.

7. Jennifer H, Bruce A, Cheryl S, Raouf W, John J, et al. (2009) Intranenous nitroglycerin for external cephalic version. Obstet Gynaecol 114: 560-567.

8. Marjolein K, Joke MB, Jan M.van L, D imitri MP, Gunilla K, et al. Nifedipine as a uterine relaxant for external cephalic version: a randomized controlled trial. Obstet Gynecol 112: 271-276.

9. Marc B, Emmanuel B, Gerald P, Yannik V (2003) The relationship between amniotic fluid index and successful external cephalic version: $A$ 14-yearexpeience. Am J Obstet Gynecol 189: 751-754.

10. Hutton EK, Kaufman K, Hodnett E, Amankwah K, Hewson SA, et al. (2003) External cephalic version beginning at 34 weeks' gestation versus 37 weeks' gestation: a randomized multicenter trial. Am J Obstet Gynecol 189: 245-254.

11. Kim G, Marjolein K, Guid O, Ben WJ, Joris A van der Post (2008) External cephalic version-related risks: a meta-analysis. Obstet Gynaecol 112: 11431151. 